\title{
Analysis of Bending Deflections of Functionally Graded Beams by Using Different Beam Theories and Symmetric Smoothed Particle Hydrodynamics
}

\author{
Armagan Karamanli* \\ *Department of Mechatronics Engineering, Faculty of Engineering and Architecture, Istanbul Gelisim University, 34215 \\ Istanbul, Turkey. \\ (afkaramanli@gelisim.edu.tr) \\ ${ }^{\ddagger}$ Corresponding Author; Armagan Karamanli, Department of Mechatronics Engineering, Faculty of Engineering and \\ Architecture, Istanbul Gelisim University, 34215 Istanbul, Turkey, Tel: +90 2124227020, armagan_k@yahoo.com
}

Received: 28.07.2016 Accepted: 02.09.2016

\begin{abstract}
The elastostatic deformations of functionally graded beams under various boundary conditions are investigated by using different beam theories and the Symmetric Smoothed Particle Hydrodynamics (SSPH) method. The numerical calculations are performed based on the Euler-Bernoulli, Timoshenko and Reddy-Bickford beam theories. The performance of the SSPH method is investigated for the comparison of the different beam theories where the beams are composed of two different materials for the first time. For the numerical results various numbers of nodes are used in the problem domain. Regarding to the computed results for Reddy-Bickford beam theory various numbers of terms in the Taylor Series Expansions (TSEs) are employed to improve the accuracy. To validate the performance of the SSPH method, comparison studies in terms of transverse deflections are carried out with the analytical solutions by using the global $\mathrm{L}_{2}$ error norm.
\end{abstract}

Keywords Meshless method, functionally graded beam, bending deflection, SSPH method, shear deformation theories.

\section{Introduction}

One of the biggest problems that the engineers face with during the new product development process is the selecting of the proper material to be used for the engineering applications. There are many factors to be considered for the optimization of the selection process such as the cost of raw material and production, fabrication techniques, logistics, material properties, requirements of customers with severe operating conditions for instance; the material should be hard but also ductile or the material can withstand very high surface temperature of $2000 \mathrm{~K}$ and a temperature gradient of $1000 \mathrm{~K}$ across a $10 \mathrm{~mm}$ thickness and so on. In 1984, a group of Japanese scientists working on a space shuttle project requiring a thermal barrier with high performance properties introduced a novel material called Functionally Graded Material (FGM). FGMs can be classified as advanced materials which are inhomogeneous and made up of two (or more) different materials combined in solid states with varying properties as the dimension changes.
The engineering applications where the FGMs may be used are the aerospace, biomedical, defence, energy, optoelectronics, automotive (engine components), turbine blade, reactor components (nuclear energy) and etc. FGMs may be used in different application areas with the development of new fabrication technologies, the reduction in cost of production, improvement in the properties of FGMs.

The advantages of the FGMs over the conventional and classical composite materials are basically due to varying material properties over a changing dimension which allows enhancing the bond strength through the layer interfaces, high resistance to temperature shocks, lower transverse shear stresses, etc. Researchers have been devoted a considerable number of studies to predict and to understand the mechanics of the FGM structures.

An elasticity solution of a FGM beam subjected to transverse loads based on the Euler Bernoulli Beam Theory (EBT) is given in [1]. By using the semi inverse method, a closed form 2D plane elasticity solution of a cantilever beam 
with different loading conditions and gradation laws can be found in [2]. In [3], the analytical solution of a 2D plane stress problem for a Functionally Graded Beam (FGB) subjected to normal and shear tractions of arbitrary form on the top and bottom surfaces and under various end boundary conditions is presented. The bending solutions of the generally anisotropic beams with elastic compliance parameters being arbitrary functions of the thickness coordinate are investigated in [4]. The static behaviour of FGBs under ambient temperature by using the higher order beam theory is studied extensively in [5] for the transverse displacements, axial stress and transverse shear stress distribution. The static and dynamic behaviours of functionally graded Timoshenko and Euler-Bernoulli beams are investigated by introducing a new function which helps to decouple the governing equations and allows representing the transverse deflection and rotational angle only in the terms of this new function [6]. The static response of functionally graded material short beam is studied in [7] using the parabolic shear deformation theory and sinusoidal shear deformation theory to show the ability of higher order theories to enhance predictions provided by classical beam theories. The flexional bending of a simply supported FGB is studied by using different higher order beam theories with varying gradation laws [8]. The refined beam theories are introduced for the static analysis of the FGBs whose properties are graded along one or two directions in [9]. The determination of the shear correction factor is investigated in [10] for various gradation laws. The static bending solutions of the FGM Timoshenko Beams are obtained analytically in terms of the homogeneous Euler Bernoulli beams by using mathematical similarity and load equivalence between the governing equations [11]. The static behaviour of the FGBs are also studied by using the quasi-3D theory to show the effects of shear deformation and thickness stretching on the displacement and stresses [12]. Several refined beam finite elements obtained by means of the Carrera Unified Formulation (CUF) are used to static analysis of the FGBs [13]. In 14, the combination of the Timoshenko Beam Theory (TBT) and the finite volume method is developed for the static and the free vibration of the FGBs. Due to the different implementation areas of the FGMs in engineering applications, free and forced vibration [15-26] and buckling behaviour [27-34] of the functionally graded structures have been extensively investigated by several researchers.

As it is seen form above discussions, the studies related to analytical and semi-analytical solutions of these initial and boundary value problems which have complex governing equations are very limited in the literature. Therefore, one may easily show that the numerical methods such as finite element methods (FEM), meshless methods, GDQM, etc. are widely used and have shown great progress for the analysis of these complex problems. However, for convenience and generality considerations at least to the best of the author's knowledge, there is no common agreement and also no reported work regarding to the meshless methods of which best fit in terms of accuracy, CPU time, flexibility for dealing with the complex geometries, extendibility to multidimensional problems and etc., for the static and dynamic analysis of the FGBs based on the different beam theories.
Meshless methods are the most promising and have attracted considerable attention for the analysis of engineering problems with intrinsic complexity. Meshless methods are widely used in static and dynamic analyses of the isotropic, laminated composite and FGM beam problems [35-41]. To obtain the approximate solution of the problem by a meshless method, the selection of the basis functions is almost the most important issue. The accuracy of the computed solution can be increased by employing different number of terms in TSE or increasing number of nodes in the problem domain or by increasing the degree of complete polynomials. Many meshless methods have been proposed by researchers to obtain the approximate solution of the problem. The Smoothed Particle Hydrodynamics (SPH) method is proposed by Lucy [42] to the testing of the fission hypothesis. However, this method has two important shortcomings, lack of accuracy on the boundaries and the tensile instability. To remove these shortcomings, many meshless methods have been proposed by several researchers [43-63].

The main scope of this work is to evaluate the performance of the SSPH method employing the strong formulation for the static transverse deflection analysis of the FGBs based on various beam theories such as EBT, TBT and the Reddy - Bickford Beam Theory (RBT). To provide a fair and comparable evaluation, two FGB problems of which analytical solutions are available in the literature will be used for the numerical calculations.

Based on the above discussions, the main novelty of this work is that there is no reported work on the bending deflections of the functionally graded beams subjected to the different boundary conditions by using the SSPH method. Since the basis functions and the derivatives of these functions are obtained simultaneously and the usage of a constant weight function is possible to obtain the approximate solution, the SSPH method has an advantage over the Moving Least Squares, Reproducing Kernel Particle Method, Modified Smoothed Particle Hydrodynamics and the Strong Form Meshless Implementation of Taylor Series Method [51-56].

In section 2, the formulation of the basis function of the SSPH method is given. In section 2, the homogenization of material properties of the FGB is presented. The formulation of the EBT, TBT and RBT based on the FGM and the SSPH method are given in Section 4. In Section 5, numerical results are given based on the two FGB problems which are a simply supported FGB under uniformly distributed load and a cantilever FGB under the uniformly distributed load. The performance of the SSPH method is evaluated by using the analytical solutions of studied problems.

\section{Formulation of Symmetric Smoothed Particle Hydrodynamics}

Taylor Series Expansion (TSE) of a scalar function for $1 \mathrm{D}$ case can be given by

$f(\xi)=\sum_{m=0}^{n} \frac{1}{m !}\left[(\xi-x) \frac{d}{d x}\right]^{m} f(x)$ 
where $f(\xi)$ is the value of the function at $\xi$ located in near of $x$. If the zeroth to sixth order terms are employed and the higher order terms are neglected, the equation (1) can be written as follows,

$f(\xi)=P(\xi, x) Q(x)$

where

$Q(x)=\left[f(x), \frac{d f(x)}{d x_{1}}, \frac{1}{2 !} \frac{d^{2} f(x)}{d x_{1}{ }^{2}}, \ldots, \frac{1}{6 !} \frac{d^{6} f(x)}{d x_{1}{ }^{6}}\right]^{T}$

$P(\xi, x)=\left[1,\left(\xi_{1}-x_{1}\right),\left(\xi_{1}-x_{1}\right)^{2}, \ldots,\left(\xi_{1}-x_{1}\right)^{6}\right]$

To determine the unknown variables given in the $\mathrm{Q}(\mathrm{x})$, both sides of equation (2) are multiplied with $\mathrm{W}(\xi, \mathrm{x}) \mathrm{P}(\xi, \mathrm{x})^{\mathrm{T}}$ and evaluated for every node in the CSD. In the global numbering system, let the particle number of the $k$ th particle in the compact support of $\mathrm{W}(\xi, \mathrm{x})$ be $\mathrm{r}(\mathrm{k})$. The following equation is obtained

$\sum_{k=1}^{N(x)} f\left(\xi^{r(k)}\right) W\left(\xi^{r(k)}, x\right) P\left(\xi^{r(k)}, x\right)^{T}$

$=\sum_{k=1}^{N(x)}\left[P\left(\xi^{r(k)}, x\right)^{T} W\left(\xi^{r(k)}, x\right) P\left(\xi^{r(k)}, x\right)\right] Q(x)$

where $\mathrm{N}(\mathrm{x})$ is the number nodes in the compact support domain (CSD) of the $\mathrm{W}(\xi, \mathrm{x})$ as shown in Fig.1.

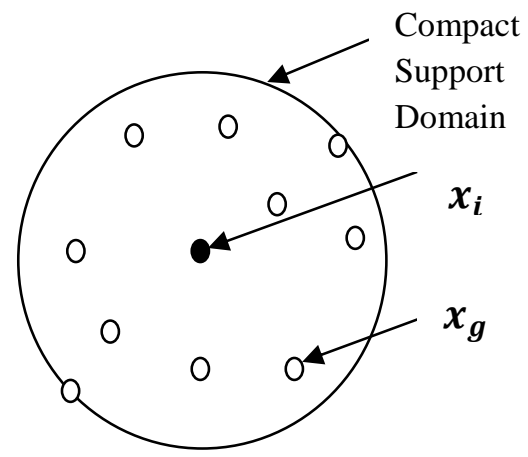

Fig. 1. Compact support of the weight function $W(\xi, x)$ for the node located at $\mathrm{x}=\left(\mathrm{x}_{\mathrm{i}}, \mathrm{y}_{\mathrm{i}}\right)$

Then, equation (5) can be given by

$C(\xi, x) Q(x)=D(\xi, x) F^{(x)}(\xi, x)$

where $\quad \mathrm{C}(\xi, \mathrm{x})=\mathrm{P}(\xi, \mathrm{x})^{\mathrm{T}} \mathrm{W}(\xi, \mathrm{x}) \mathrm{P}(\xi, \mathrm{x})$ and $\quad \mathrm{D}(\xi, \mathrm{x})=$ $\mathrm{P}(\xi, \mathrm{x})^{\mathrm{T}} \mathrm{W}(\xi, \mathrm{x})$.

The solution of equation (6) is given by

$Q(x)=K(\xi, x) F(\xi)$

where $\mathrm{K}^{(\mathrm{x})}(\xi, \mathrm{x})=\mathrm{C}(\xi, \mathrm{x})^{-1} \mathrm{D}(\xi, \mathrm{x})$. Equation (7) can be also written as follows

$Q_{I}(x)=\sum_{J=1}^{M} K_{I J} F_{J}, \quad I=1,2, \ldots, 6$

Where $M$ is the number of nodes and $F_{J}=f\left(\xi^{J}\right)$. Seven components of equation (8) for 1D case are can be written as

$f(x)=Q_{1}(x)=\sum_{J=1}^{M} K_{1 J} F_{J}$

$\frac{d f(x)}{d x}=Q_{2}(x)=\sum_{J=1}^{M} K_{2 J} F_{J}$

$\frac{d^{2} f(x)}{d x^{2}}=2 ! Q_{3}(x)=\sum_{J=1}^{M} K_{3 J} F_{J}$ $\frac{d^{3} f(x)}{d x^{3}}=3 ! Q_{4}(x)=\sum_{J=1}^{M} K_{4 J} F_{J}$

$\frac{d^{4} f(x)}{d x^{4}}=4 ! Q_{5}(x)=\sum_{J=1}^{M} K_{5 J} F_{J}$

$\frac{d^{5} f(x)}{d x^{5}}=5 ! Q_{6}(x)=\sum_{J=1}^{M} K_{6 J} F_{J}$

$\frac{d^{6} f(x)}{d x^{6}}=6 ! Q_{7}(x)=\sum_{J=1}^{M} K_{7 J} F_{J}$

The formulation of the SSPH method can be found in [52-57].

\section{Homogenization of Material Properties}

We assume that the beam of length $L$, width $b$, thickness $\mathrm{h}$ is made of two randomly distributed different isotropic constituents. Further, the macroscopic response of the FGB is isotropic and the material parameters vary only in $\mathrm{Z}$ direction as shown in Fig. 2. The rule of mixture is used to find the effective material properties at a point. According to the rule of mixtures, the effective material properties of the beam, Young's modulus $\mathrm{E}$ and shear modulus $\mathrm{G}$ can be given by

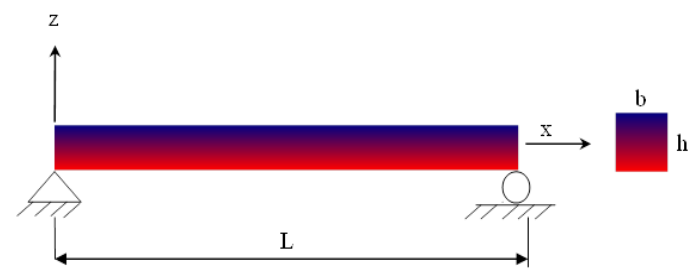

Fig. 2. Geometry of the FGB composed of two isotropic constituents

$E(z)=E_{1} V_{1}(z)+E_{2} V_{2}(z)$

$G(z)=G_{1} V_{1}(z)+G_{2} V_{2}(z)$

where $E_{1}, E_{2}, G_{1}$ and $G_{2}$ are the material properties of two constituents, $V_{1}$ and $V_{2}$ are volüme fractions of the constituents. The relation of the volume fractions can be expressed as follows;

$V_{1}(z)+V_{2}(z)=1$

According to the power law form, the volume fraction of the constitute 1 can be given by

$V_{1}(z)=\left(\frac{1}{2}+\frac{z}{h}\right)^{p}$

where $\mathrm{p}$ is the gradation exponent which determines the material property through thickness of the beam. At the bottom surface of the beam, the volume fraction of the constitute 1 is zero, $V_{1}=0$. At the top surface it is found as $V_{1}=1$. The effective material properties can be found by using the equations (10), (11) and (12) as follows

$E(z)=\left(E_{1}-E_{2}\right)\left(\frac{1}{2}+\frac{z}{h}\right)^{p}+E_{2}$

$G(z)=\left(G_{1}-G_{2}\right)\left(\frac{1}{2}+\frac{z}{h}\right)^{p}+G_{2}$

\section{Formulation of Beam Theories}


The kinematics of deformation of a beam can be represented by using various beam theories. Among them, the EBT, TBT and RBT are commonly used [64-67]. Various higher order beam theories are introduced in which the straightness assumption is removed and the vanishing of shear stress at the upper and lower surfaces is accommodated. For this purpose, higher order polynomials incorporating either one, or more, extra terms [68-74] or trigonometric functions [75,76] or exponential functions [77] are included in the expansion of the longitudinal point-wise displacement component through the thickness of the beam. The higher order theories introduce additional unknowns that make the governing equations more complicated and provide the solutions much costly in terms of CPU time. The theories which are higher than the third order shear deformation beam theory are seldom used because the accuracy gained by these theories which require much effort to solve the governing equations is so little [66].

\subsection{Euler Bernoulli Beam Theory}

The following displacement field is given for the EBT,

$u(x, z)=-z \frac{d w}{d x}$

$w(x, z)=w_{0}(x)$

where $\mathrm{w}_{0}$ is the transverse deflection of the point $(\mathrm{x}, 0)$ which is on the mid-plane $(\mathrm{z}=0)$ of the beam. By using the assumption of the smallness of strains and rotations, the only the axial strain which is nonzero is given by,

$\varepsilon_{x x}=\frac{d u}{d x}=-z \frac{d^{2} w_{0}}{d x^{2}}$

The virtual strain energy of the beam in terms of the axial stress and the axial strain can be expressed by

$\delta U=\int_{0}^{L} \int_{A} \sigma_{x x} \delta \varepsilon_{x x} d A d x$

where $\delta$ is the variation operator, $\mathrm{A}$ is the cross sectional area, $\mathrm{L}$ is the length of the beam, $\sigma_{x x}$ is the axial stress. The bending moment of the EBT is given by,

$M_{x x}=\int_{A} z \sigma_{x x} d A$

By using equation (15) and equation (17), equation (16) can be rewritten as,

$\delta U=-\int_{0}^{L} M_{x x} Z \frac{d^{2} \delta w_{0}}{d x^{2}}$

The virtual potential energy of the load $q(x)$ which acts at the central axis of the beam is given by

$\delta V=-\int_{0}^{L} q(x) \delta w_{0} d x$

If a body is in equilibrium, $\delta \mathrm{W}=\delta \mathrm{U}+\delta \mathrm{V}$, the total virtual work $(\delta \mathrm{W})$ done equals zero. Then one can obtain,

$\delta W=-\int_{0}^{L}\left(M_{x x} Z \frac{d^{2} \delta w_{0}}{d x^{2}}+q(x) \delta w_{0}\right) d x=0$

After performing integration for the first term in equation (20) twice and since $\delta w_{0}$ is arbitrary in $(0<\mathrm{x}<\mathrm{L})$, one can obtain the following equilibrium equation, $-\frac{d^{2} M_{x x}}{d x^{2}}=q(x)$ for $0<x<L$

By introducing the shear force $Q_{x}$ and rewrite equation (21) in the following form

$-\frac{d M_{x x}}{d x}+Q_{x}=0, \quad-\frac{d Q_{x}}{d x}=q(x)$

By using Hooke's law, one can obtain

$$
\sigma_{x x}=E(z) \varepsilon_{x x}=-\left[\left(E_{1}-E_{2}\right)\left(\frac{1}{2}+\frac{z}{h}\right)^{p}+E_{2}\right] z \frac{d^{2} w_{0}}{d x^{2}}
$$

If the equation (23) is put into equation (17), it is obtained,

$M_{x x}=-\int_{-h / 2}^{+h / 2}\left[\left(E_{1}-E_{2}\right)\left(\frac{1}{2}+\frac{z}{h}\right)^{p}+E_{2}\right] z^{2} \frac{d^{2} w_{0}}{d x^{2}} d z=$

$-D_{x x} \frac{d^{2} w_{0}}{d x^{2}}$

where

$D_{x x}=\int_{-h / 2}^{+h / 2}\left[\left(E_{1}-E_{2}\right)\left(\frac{1}{2}+\frac{z}{h}\right)^{p}+E_{2}\right] z^{2} d z$

The substitution of equation (24) into equation (22) yields the EBT governing equation for a FGB subjected to the distributed load

$\frac{d^{2}}{d x^{2}}\left(D_{x x} \frac{d^{2} w_{0}}{d x^{2}}\right)=q(x)$ for $0<x<L$

\subsection{Timoshenko Beam Theory}

The following displacement field is given for the TBT,

$u(x, z)=z \phi(x)$

$w(x, z)=w_{0}(x)$

where $\phi(x)$ is the rotation of the cross section. By using equation (27), the strain-displacement relations are given by

$\varepsilon_{x x}=\frac{d u}{d x}=-z \frac{d \phi}{d x}$

$\gamma_{x z}=\frac{d u}{d z}+\frac{d w}{d x}=\phi+\frac{d w_{0}}{d x}$

The virtual strain energy of the beam including the virtual energy associated with the shearing strain can be written as,

$\delta U=\int_{0}^{L} \int_{A}\left(\sigma_{x x} \delta \varepsilon_{x x}+\sigma_{x z} \delta \gamma_{x z}\right) d A d x$

where $\sigma_{x z}$ is the transverse shear stress and $\gamma_{x z}$ is the shear strain. The bending moment and the shear force can be written respectively,

$$
M_{x x}=\int_{A} z \sigma_{x x} d A, \quad Q_{x}=\int_{A} \sigma_{x z} d A
$$

By using equation (28) and equation (30), one can rewrite equation (29) as,

$\delta U=\int_{0}^{L}\left[M_{x x} \frac{d \delta \phi}{d x}+Q_{x}\left(\delta \phi+\frac{d \delta w_{0}}{d x}\right)\right] d x$

The virtual potential energy of the load $q(x)$ which acts at the central axis of the Timoshenko beam is given by

$\delta V=-\int_{0}^{L} q(x) \delta w_{0} d x$ 
Since the total virtual work done equals zero and the coefficients of $\delta \phi$ and $\delta w_{0}$ in $0<\mathrm{x}<\mathrm{L}$ are zero, one can obtain the following equations,

$-\frac{d M_{x x}}{d x}+Q_{x}=0, \quad-\frac{d Q_{x}}{d x}=q(x)$

The constitutive equations can be written as follows

$\sigma_{x x}=E(z) \varepsilon_{x x}=\left[\left(E_{1}-E_{2}\right)\left(\frac{1}{2}+\frac{z}{h}\right)^{p}+E_{2}\right] z \frac{d \phi}{d x}$

$\sigma_{x z}=G(z) \gamma_{x z}=\left[\left(G_{1}-G_{2}\right)\left(\frac{1}{2}+\frac{z}{h}\right)^{p}+G_{2}\right]\left(\phi+\frac{d w_{0}}{d x}\right)$

The bending moment and shear force can be expressed in terms of generalized displacement $\left(w_{0}, \phi\right)$ by using the constitutive equations given above

$M_{x x}=\int_{-h / 2}^{+h / 2} z \sigma_{x x} d z=\int_{-h / 2}^{+h / 2}\left[\left(E_{1}-E_{2}\right)\left(\frac{1}{2}+\frac{z}{h}\right)^{p}+\right.$

$\left.E_{2}\right] z^{2} \frac{d \phi}{d x} d z=D_{x x} \frac{d \phi}{d x}$

$Q_{x}=\kappa_{s} \int_{-\frac{h}{2}}^{+\frac{h}{2}} \sigma_{x z} d z=\kappa_{s} \int_{-\frac{h}{2}}^{+\frac{h}{2}}\left[\left(G_{1}-G_{2}\right)\left(\frac{1}{2}+\frac{z}{h}\right)^{p}+\right.$

$\left.G_{2}\right]\left(\phi+\frac{d w_{0}}{d x}\right) d z=\kappa_{s} A_{x z}\left(\phi+\frac{d w_{0}}{d x}\right)$

where

$D_{x x}=\int_{-h / 2}^{+h / 2}\left[\left(E_{1}-E_{2}\right)\left(\frac{1}{2}+\frac{z}{h}\right)^{p}+E_{2}\right] z^{2} d z$

$A_{x z}=\int_{-\frac{h}{2}}^{+\frac{h}{2}}\left[\left(G_{1}-G_{2}\right)\left(\frac{1}{2}+\frac{z}{h}\right)^{p}+G_{2}\right] d z$

Where $\kappa_{s}$ is the shear correction factor which is used to compensate the error caused by the assumption of a constant transverse shear stress distribution along the beam thickness.

The governing equations of the TBT is obtained in terms of generalized displacements by using the equations (33) and (36) as follows

$-\frac{d}{d x}\left(D_{x x} \frac{d \phi}{d x}\right)+\kappa_{s} A_{x z}\left(\phi+\frac{d w_{0}}{d x}\right)=0$

$-\frac{d}{d x}\left[\kappa_{S} A_{x z}\left(\phi+\frac{d w_{0}}{d x}\right)\right]=q(x)$

\subsection{Reddy-Bickford Beam Theory}

The following displacement field is given for the RBT,

$u(x, z)=z \phi(x)-\alpha z^{3}\left(\phi(x)+\frac{d w(x)}{d x}\right)$

$w(x, z)=w_{0}(x)$

where $\alpha=4 /\left(3 h^{2}\right)$. By using equation (41), the straindisplacement relations of the RBT are given by

$\varepsilon_{x x}=\frac{d u}{d x}=z \frac{d \phi}{d x}-\alpha z^{3}\left(\frac{d \phi}{d x}+\frac{d^{2} w_{0}}{d x^{2}}\right)$

$\gamma_{x z}=\frac{d u}{d z}+\frac{d w}{d x}=\phi+\frac{d w_{0}}{d x}-\beta z^{2}\left(\phi+\frac{d w_{0}}{d x}\right)$

where $\beta=3 \alpha=4 /\left(h^{2}\right)$.

The virtual strain energy of the beam can be written as,

$\delta U=\int_{0}^{L} \int_{A}\left(\sigma_{x x} \delta \varepsilon_{x x}+\sigma_{x z} \delta \gamma_{x z}\right) d A d x$
The usual bending moment and the shear force are,

$M_{x x}=\int_{A} z \sigma_{x x} d A, \quad Q_{x}=\int_{A} \sigma_{x z} d A$

and $P_{x x}$ and $R_{x}$ are the higher order stress resultants can be written respectively,

$P_{x x}=\int_{A} z^{3} \sigma_{x x} d A, \quad R_{x}=\int_{A} z^{2} \sigma_{x z} d A$

By using equation (41), equation (43) and equation (44), one can rewrite the equation (42) as,

$\delta U=\int_{0}^{L}\left[\left(M_{x x}-\alpha P_{x x}\right) \frac{d \delta \phi}{d x}-\alpha P_{x x} \frac{d^{2} \delta w_{0}}{d x^{2}}+\left(Q_{x}-\right.\right.$

$\left.\left.\beta R_{x}\right)\left(\delta \phi+\frac{d \delta w_{0}}{d x}\right)\right] d x$

In the RBT there is no need to use a SCF unlike the TBT. The virtual potential energy of the transverse load $q(x)$ is given by

$\delta V=-\int_{0}^{L} q(x) \delta w_{0} d x$

The virtual displacements principle is applied and the coefficients of $\delta \phi$ and $\delta w_{0}$ in $0<\mathrm{x}<\mathrm{L}$ are set to zero, the governing equations of the RBT are obtained in terms of displacements $\phi$ and $w_{0}$ as follows,

$-\frac{d}{d x}\left(\bar{D}_{x x} \frac{d \phi}{d x}-\alpha \hat{F}_{x x} \frac{d^{2} w_{0}}{d x^{2}}\right)+\bar{A}_{x z}\left(\phi+\frac{d w_{0}}{d x}\right)=0$

$-\alpha \frac{d^{2}}{d x^{2}}\left(\hat{F}_{x x} \frac{d \phi}{d x}-\alpha H_{x x} \frac{d^{2} w_{0}}{d x^{2}}\right)-\frac{d}{d x}\left[\bar{A}_{x z}\left(\phi+\frac{d w_{0}}{d x}\right)\right]=q(x)$

where

$\bar{A}_{x z}=\hat{A}_{x z}-\beta \widehat{D}_{x z}, \quad \bar{D}_{x x}=\widehat{D}_{x x}-\alpha \hat{F}_{x x}$

$\widehat{D}_{x x}=D_{x x}-\alpha F_{x x}, \quad \hat{F}_{x x}=F_{x x}-\alpha H_{x x}$

$\hat{A}_{x z}=A_{x z}-\beta D_{x z}, \widehat{D}_{x z}=D_{x z}-\beta F_{x z}$

$\left(D_{x x}, F_{x x}, H_{x x}\right)=$

$\int_{-\frac{h}{2}}^{+\frac{h}{2}}\left[\left(E_{1}-E_{2}\right)\left(\frac{1}{2}+\frac{z}{h}\right)^{p}+E_{2}\right]\left(z^{2}, z^{4}, z^{6}\right) d z$

$\left(A_{x Z}, D_{x Z}, F_{x Z}\right)=$

$\int_{-h / 2}^{+h / 2}\left[\left(G_{1}-G_{2}\right)\left(\frac{1}{2}+\frac{z}{h}\right)^{p}+G_{2}\right]\left(1, z^{2}, z^{4}\right) d z$

\section{Numerical Results}

The bending deflections of two FGB problems are investigated by using the formulation of the EBT, TBT and RBT and the SSPH method. Different loading and boundary conditions are applied with different node distributions in the problem domain. By employing different aspect ratios and gradation exponents, the maximum transverse deflections are calculated. The numerical results obtained by the SSPH method regarding to different beam theories are compared with the analytical solution of problems.

\subsection{Simply Supported Beam}


Static transverse deflections of a simply supported FGB under uniformly distributed load of intensity $q_{0}$ as shown in Fig.3. is studied.

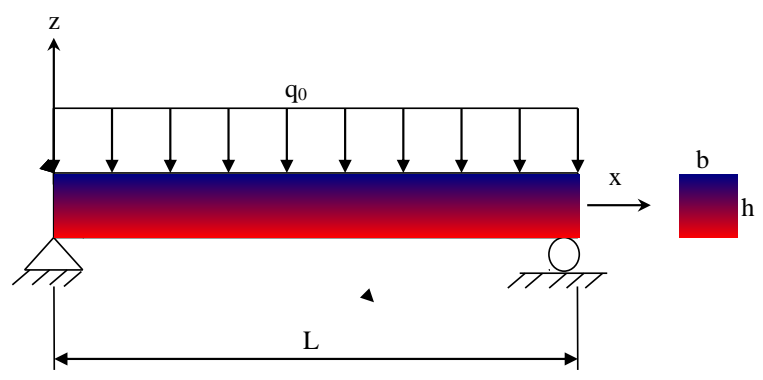

Fig. 2. Simply supported fgb with uniformly distributed load

The physical parameters of the beam are given as $\mathrm{L}=1 \mathrm{~m}$, $\mathrm{h}=0.1 \mathrm{~m}, \mathrm{~b}=0.1 \mathrm{~m}$. The distributed load $q_{0}$ is set to 10000 $\mathrm{N} / \mathrm{m}$. The material properties of the two constitutes are given as

$$
E_{1}=70 G P a, E_{2}=151 G P a, G_{1}=27 G P a, G_{2}=58 G P a
$$

Based on the EBT, the governing equation of the problem can be presented as algebraic equations by using the SSPH basis function given in equation (9) and replacing $f(x)$ with $w_{0}(x)$ as follows,

$D_{x x} \sum_{J=1}^{M} 24 K_{5 J} W_{J}=q_{0} \quad$ for $0<x<L$

The boundary conditions regarding to the EBT are given as follows;

$$
\begin{aligned}
& x=0, \quad \sum_{J=1}^{M} 2 K_{3 J} W_{J}=0 \text { and } \sum_{J=1}^{M} K_{1 J} W_{J}=0 \mathrm{~m} \\
& x=L, \quad \sum_{J=1}^{M} 2 K_{3 J} W_{J}=0 \text { and } \sum_{J=1}^{M} K_{1 J} W_{J}=0 \mathrm{~m}
\end{aligned}
$$

The analytical solution of this boundary value problem based on the EBT is given by

$w_{0}^{E}(x)=\frac{q_{0} L^{4}}{24 D_{x x}}\left(\frac{x}{L}-\frac{2 x^{3}}{L^{3}}+\frac{x^{4}}{L^{4}}\right)$

where the superscript $E$ denotes the quantities in the EBT.

The governing equations of the problem can be written in a similar way by replacing $f(x)$ given in equation (9) with $w_{0}(x)$ and $\phi(x)$ and by using the SSPH basis functions as follows,

$\sum_{J=1}^{M} \kappa_{S} A_{x z} K_{2 J} W_{J}+\sum_{J=1}^{M}\left[\kappa_{s} A_{x z} K_{2 J}-2 D_{x x} K_{3 J}\right] \Phi_{J}=0(51)$

$-\sum_{J=1}^{M} 2 \kappa_{s} A_{x z} K_{3 J} W_{J}-\sum_{J=1}^{M} \kappa_{s} A_{x z} K_{2 J} \Phi_{J}=q_{0}$

The SCF is assumed to be constant as $\kappa_{s}=5 / 6$ for the rectangular cross section,

The boundary conditions regarding to the TBT are given as follows;

$$
\begin{aligned}
& x=0, \quad \sum_{J=1}^{M} K_{2 J} \Phi_{J}=0 \text { and } \sum_{J=1}^{M} K_{1 J} W_{J}=0 \mathrm{~m} \\
& x=L, \quad \sum_{J=1}^{M} K_{2 J} \Phi_{J}=0 \text { and } \sum_{J=1}^{M} K_{1 J} W_{J}=0 \mathrm{~m}
\end{aligned}
$$

The analytical solution of this boundary value problem based on the TBT is given by

$$
w_{0}^{T}(x)=\frac{q_{0} L^{4}}{24 D_{x x}}\left(\frac{x}{L}-\frac{2 x^{3}}{L^{3}}+\frac{x^{4}}{L^{4}}\right)+\frac{q_{0} L^{2}}{2 \kappa_{S} A_{x z}}\left(\frac{x}{L}-\frac{x^{2}}{L^{2}}\right)
$$

where the superscript $T$ denotes the quantities in the TBT.

By using RBT and the SSPH basis functions the governing equations can be written by replacing $f(x)$ given in equation (9) with $w_{0}(x)$ and $\phi(x)$ as follows,

$\sum_{J=1}^{M}\left[\bar{A}_{x z} K_{2 J}+6 \alpha \hat{F}_{x x} K_{4 J}\right] W_{J}+\sum_{J=1}^{M}\left[\bar{A}_{x z} K_{1 J}-\right.$

$\left.2 \bar{D}_{x x} K_{3 J}\right] \Phi_{J}=0$

$\sum_{J=1}^{M}\left[-2 \bar{A}_{x Z} K_{3 J}+24 \alpha^{2} H_{x x} K_{4 J}\right] W_{J}+\sum_{J=1}^{M}\left[-\bar{A}_{x Z} K_{2 J}-\right.$ $\left.6 \alpha \hat{F}_{x x} K_{4 J}\right] \Phi_{J}=q$

The boundary conditions regarding to the TBT are given as follows;

$$
\begin{aligned}
& x=0, \sum_{J=1}^{M} \widehat{D}_{x x} K_{2 J} \Phi_{J}-\sum_{J=1}^{M} 2 \alpha F_{x x} K_{3 J} W_{J}=0, \\
& \text { and } \quad \sum_{J=1}^{M} K_{1 J} W_{J}=0 \mathrm{~m} \\
& x=L, \sum_{J=1}^{M} \widehat{D}_{x x} K_{2 J} \Phi_{J}-\sum_{J=1}^{M} 2 \alpha F_{x x} K_{3 J} W_{J}=0, \\
& \text { and } \quad \sum_{J=1}^{M} K_{1 J} W_{J}=0 \mathrm{~m}
\end{aligned}
$$

The analytical solution of this boundary value problem based on the RBT is given by

$$
\begin{aligned}
& w_{0}{ }^{R}(x)=\frac{q_{0} L^{4}}{24 D_{x x}}\left(\frac{x}{L}-\frac{2 x^{3}}{L^{3}}+\frac{x^{4}}{L^{4}}\right)+ \\
& \left(\frac{q_{0} \mu}{\lambda^{4}}\right)\left(\frac{\widehat{D}_{x x}}{\widehat{A}_{x z} D_{x x}}\right)\left[-\tanh \left(\frac{\lambda L}{2}\right) \sinh \lambda x+\cosh \lambda x+\right. \\
& \left.\frac{\lambda^{2}}{2} x(L-x)-1\right]
\end{aligned}
$$

where

$$
\lambda^{2}=\frac{\bar{A}_{x z} D_{x x}}{\alpha\left(F_{x x} \widehat{D}_{x x}-\hat{F}_{x x} D_{x x}\right)}, \quad \mu=\frac{\widehat{A}_{x z} \widehat{D}_{x z}}{\alpha\left(F_{x x} \widehat{D}_{x x}-\widehat{F}_{x x} D_{x x}\right)}
$$

For the numerical computations performed by the SSPH method uniformly distributed 21,41 and 161 nodes are used in the domain $x \in[0,1]$. The Revised Super Gauss Function (RSGF) which gives the least $\mathrm{L}_{2}$ error norms in numerical solutions in [52] is used.

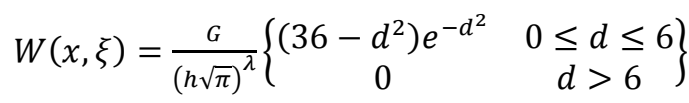

$d=|x-\xi| / h$

where $d$ is the radius of the CSD, $h$ is the smoothing length. $\mathrm{G}$ and $\lambda$ are the parameters which are eliminated by the formulation of the SSPH method.

The numerical solutions are performed according to the following meshless parameters; the radius of the support domain (d) is chosen as 6 and the smoothing length $(h)$ equals to $1.1 \Delta$ where $\Delta$ is the minimum distance between two adjacent nodes. The meshless parameters, $d$ and $h$, are selected to obtain the lowest error.

Computed results obtained by using the SSPH method are compared with the analytical solutions, and their accuracy and convergence properties are investigated by employing the global $\mathrm{L}_{2}$ error norm which is given by

$L_{2}=\frac{\left[\sum_{j=1}^{m}\left(v_{\text {num }}^{j}-v_{\text {exact }}^{j}\right)^{2}\right]^{1 / 2}}{\left[\sum_{j=1}^{m}\left(v_{\text {exact }}^{j}\right)^{2}\right]^{1 / 2}}$

The computed $\mathrm{L}_{2}$ error norms of the numerical solutions based on the EBT are given in Table 1. For the numerical 
analysis different numbers of nodes are considered in the problem domain with 5 terms in TSEs expansion and varying gradation exponents. It is observed in Table 1 that the difference between the computed and analytical results is too small and the SSPH method almost gives the analytical solution of the problem. In Table 2, maximum deflection of the FGB is presented with varying aspect ratios and gradation exponent values.

Table 1. $\mathrm{L}_{2}$ error norm for different number of nodes with varying gradation exponent (p) and aspect ratio $\mathrm{L} / \mathrm{h}=10$ EBT

\begin{tabular}{|l|l|l|l|}
\hline \multirow{2}{*}{$\begin{array}{l}\text { Gradation } \\
\text { Exponent } \\
\mathrm{p}\end{array}$} & \multicolumn{3}{|c|}{ Number of Nodes } \\
\cline { 2 - 4 } & 21 & 41 & 161 \\
\hline 0 & $3.8621 * 10^{-9}$ & $9.0384 * 10^{-8}$ & $3.6786^{*} 10^{-7}$ \\
\hline 0.5 & $3.8606^{*} 10^{-9}$ & $9.0484 * 10^{-8}$ & $3.7665^{-7} 10^{-7}$ \\
\hline 1 & $3.8636^{*} 10^{-9}$ & $9.0442^{-1} 10^{-8}$ & $3.6774 * 10^{-7}$ \\
\hline 2 & $3.8591 * 10^{-9}$ & $9.0416^{*} 10^{-8}$ & $3.7251 * 10^{-7}$ \\
\hline 5 & $3.8635^{*} 10^{-9}$ & $9.0434 * 10^{-8}$ & $3.6998^{*} 10^{-7}$ \\
\hline
\end{tabular}

Table 2. Maximum deflection ( $\mathrm{mm}$ ) of the beam with varying gradation exponent and different aspect ratios for 41 nodes - EBT

\begin{tabular}{|c|c|c|c|c|}
\hline \multirow{2}{*}{$\begin{array}{l}\text { Gradation } \\
\text { Exponent } \\
(\mathrm{p})\end{array}$} & 5 & 10 & 20 & 50 \\
\cline { 2 - 5 } & 5 & & -1.7857 & -27.9018 \\
\hline 0 & -0.0279 & -0.2232 & $-1.58 \mathrm{c}$ \\
\hline 0.5 & -0.0195 & -0.1561 & -1.2489 & -19.5145 \\
\hline 1 & -0.0176 & -0.1414 & -1.1312 & -17.6753 \\
\hline 2 & -0.0164 & -0.1317 & -1.0539 & -16.4681 \\
\hline 5 & -0.0152 & -0.1221 & -0.9776 & -15.2758 \\
\hline
\end{tabular}

Table 3. $\mathrm{L}_{2}$ error norm for different number of nodes with varying gradation exponent (p) and aspect ration $\mathrm{L} / \mathrm{h}=10$ TBT

\begin{tabular}{|c|c|c|c|}
\hline \multirow{2}{*}{$\begin{array}{l}\text { Gradation } \\
\text { Exponent } \\
(\mathrm{p})\end{array}$} & \multicolumn{3}{|c|}{ Number of Nodes } \\
\cline { 2 - 4 } & 21 & 41 & 161 \\
\hline 0 & $4.1559 * 10^{-10}$ & $3.5002 * 10^{-9}$ & $5.9457 * 10^{-9}$ \\
\hline 0.5 & $4.0629 * 10^{-10}$ & $3.5696^{-9} 10^{-9}$ & $4.8358 * 10^{-9}$ \\
\hline 1 & $3.8775 * 10^{-10}$ & $3.4994 * 10^{-9}$ & $5.6451 * 10^{-9}$ \\
\hline 2 & $4.1133 * 10^{-10}$ & $3.5803 * 10^{-9}$ & $2.8734 * 10^{-9}$ \\
\hline 5 & $3.9839 * 10^{-10}$ & $3.6220^{-9} 10^{-9}$ & $4.3202^{-9} 10^{-9}$ \\
\hline
\end{tabular}

In Fig. 3, the numerical results in terms of transverse deflections are compared with the analytical solutions with different number of nodes in the problem domain and varying gradation exponent values. The aspect ratio $(\mathrm{L} / \mathrm{h})$ is set as 50. It is observed in Fig. 4 that the SSPH method agrees very well with the analytical solution. The transverse deflection of the FGB computed by the SSPH method is virtually indistinguishable from that for the analytical solution.
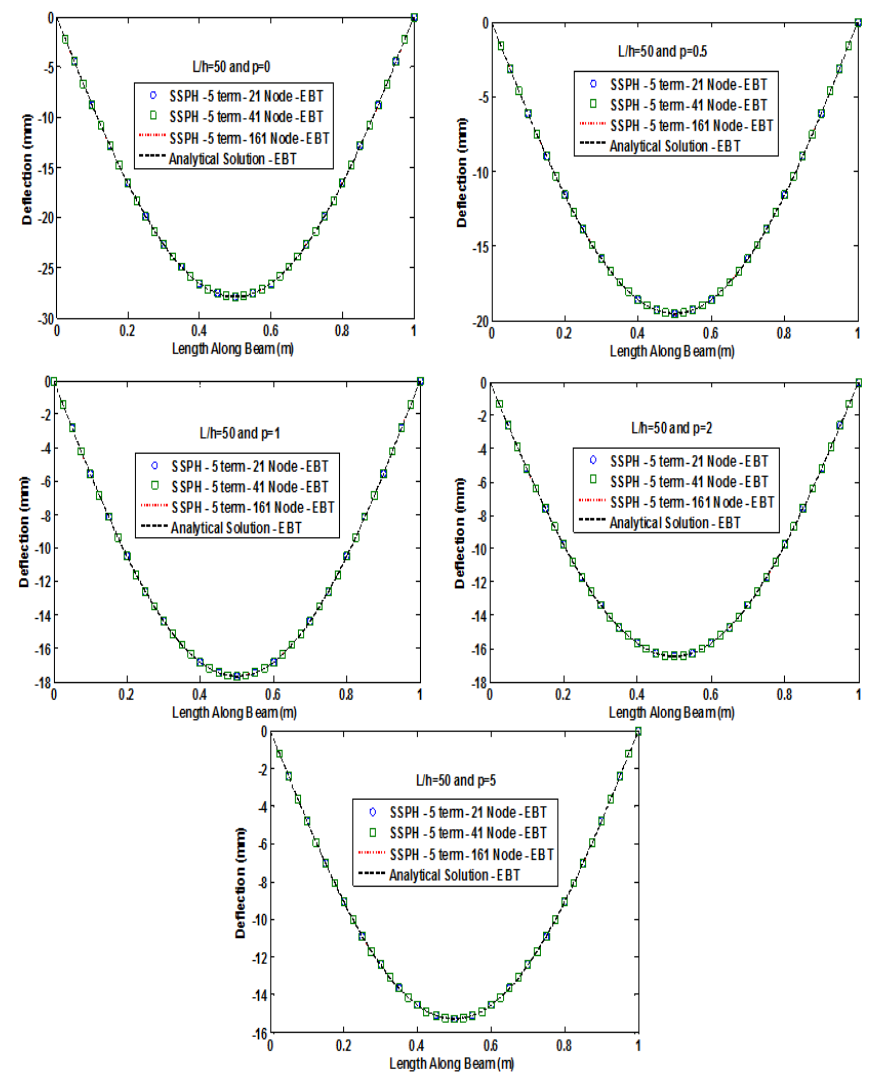

Fig. 3. Deflections of the beam computed based on the EBT with varying number of nodes and the analytical solution.

Table 4. Maximum deflection ( $\mathrm{mm}$ ) of the beam with varying gradation exponent and different aspect ratios for 41 nodes -TBT

\begin{tabular}{|l|l|l|l|l|}
\hline \multirow{2}{*}{$\begin{array}{l}\text { Gradation } \\
\text { Exponent } \\
(\mathrm{p})\end{array}$} & \multicolumn{4}{|c|}{ Aspect Ratio (L/h) } \\
\cline { 2 - 5 } & 5 & 10 & 20 & 50 \\
\hline 0 & -0.0306 & -0.2287 & -1.7968 & -27.9295 \\
\hline 0.5 & -0.0215 & -0.1601 & -1.2569 & -19.5346 \\
\hline 1 & -0.0194 & -0.1449 & -1.1383 & -17.6929 \\
\hline 2 & -0.0180 & -0.1349 & -1.0603 & -16.4839 \\
\hline 5 & -0.0166 & -0.1250 & -0.9833 & -15.2900 \\
\hline
\end{tabular}

The global $\mathrm{L}_{2}$ error norms of the solutions based on the TBT with different numbers of nodes in the problem domain, 5 terms in TSEs expansion and varying gradation exponents are given in Table 3 . One can easily notice that the computed results are very close to analytical values when global $\mathrm{L}_{2}$ error norms are investigated. The results in Table 3 are obtained for the meshless parameters $d$ and $h$ which gives the best accuracy for each method. In Table 4, maximum deflection of the FGB is presented with varying aspect ratios and gradation exponent values. As expected, the deflection value increases either an increase or a decrease for the aspect ratio and the gradation exponent. It is clear that numerical solutions obtained by the SSPH method agree very well with the analytical solution given in Fig. 5. 

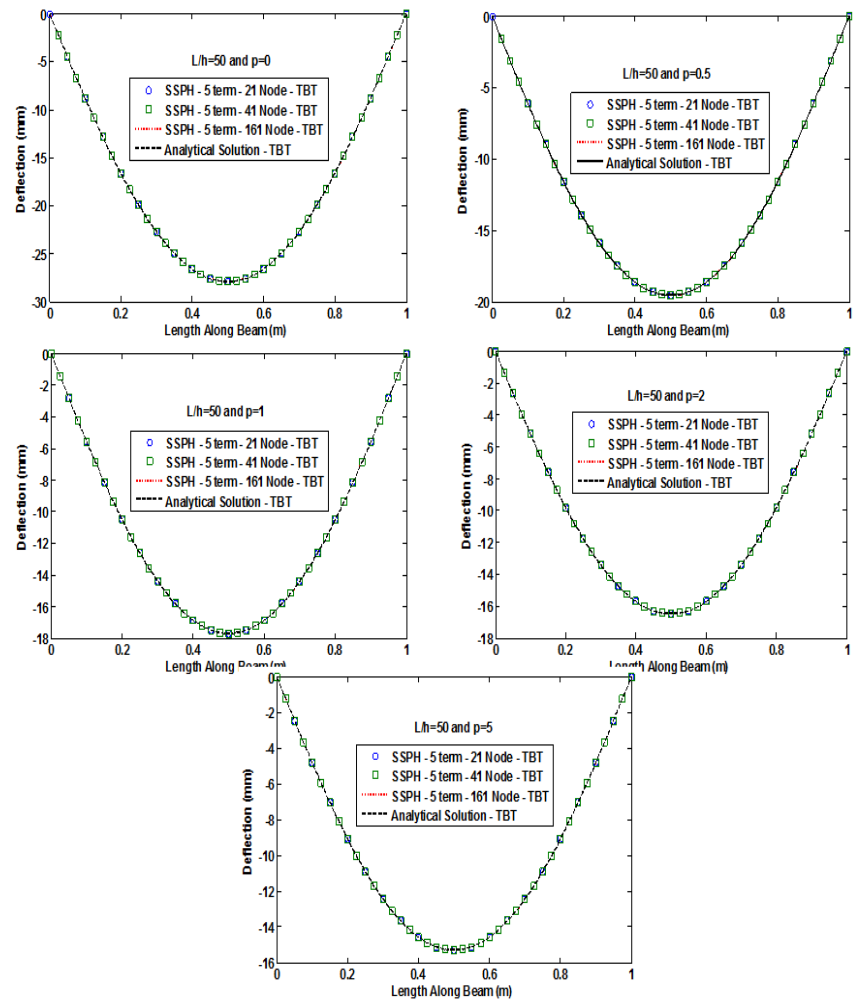

Fig. 4. Deflections of the beam computed based on the TBT and the analytical solution.

Table 5. $\mathrm{L}_{2}$ error norm for different number of nodes with varying gradation exponent $(\mathrm{p})$ and aspect ratio $\mathrm{L} / \mathrm{h}=10-5$ terms in TSEs -RBT

\begin{tabular}{|c|c|c|c|}
\hline \multirow{2}{*}{$\begin{array}{l}\text { Gradation } \\
\text { Exponent } \\
(\mathrm{p})\end{array}$} & \multicolumn{3}{|c|}{ Number of Nodes } \\
\cline { 2 - 4 } & 21 & 41 & 161 \\
\hline 0 & 2.056779 & 2.056786 & 2.056786 \\
\hline 0.5 & 2.167582 & 2.167589 & 2.167589 \\
\hline 1 & 2.064060 & 2.064066 & 2.064067 \\
\hline 2 & 1.924057 & 1.924063 & 1.924063 \\
\hline 5 & 1.845563 & 1.845569 & 1.845569 \\
\hline
\end{tabular}

Table 6. $\mathrm{L}_{2}$ error norm for different number of nodes with varying gradation exponent $(\mathrm{p})$ and aspect ratio $\mathrm{L} / \mathrm{h}=10-7$ terms in TSEs - RBT

\begin{tabular}{|c|c|c|c|}
\hline \multirow{2}{*}{$\begin{array}{c}\text { Gradation } \\
\text { Exponent (p) }\end{array}$} & \multicolumn{3}{|c|}{ Number of Nodes } \\
\cline { 2 - 4 } & 21 & 41 & 161 \\
\hline 0 & 1.7794 & 1.6913 & 0.5618 \\
\hline 0.5 & 1.8838 & 1.7994 & 0.4541 \\
\hline 1 & 1.7866 & 1.6986 & 0.5545 \\
\hline 2 & 1.6544 & 1.5619 & 0.6909 \\
\hline 5 & 1.5820 & 1.4860 & 0.7665 \\
\hline
\end{tabular}

By setting the aspect ratio as 10 , the global $\mathrm{L}_{2}$ error norms of the solutions based on the RBT are computed for different number of nodes, varying gradation exponent and different number of terms in TSEs. By using 5 terms in TSEs, the accuracy of the SSPH method is not improved when the number of nodes increases in the problem domain.
However, the convergence of the SSPH method increases when 7 terms in TSEs are employed.

Table 7. Maximum deflection ( $\mathrm{mm}$ ) of the beam with varying gradation exponent and different aspect ratios for 161 nodes - RBT

\begin{tabular}{|c|c|c|c|c|}
\hline \multirow{2}{*}{$\begin{array}{l}\text { Gradation } \\
\text { Exponent } \\
\text { (p) }\end{array}$} & \multicolumn{4}{|c|}{ Aspect Ratio (L/h) } \\
\hline & 5 & 10 & 20 & 50 \\
\hline 0 & -0.0271 & -0.2231 & -1.7524 & -27.2619 \\
\hline 0.5 & -0.0189 & -0.1562 & -1.2259 & -19.0676 \\
\hline 1 & -0.0172 & -0.1413 & -1.1101 & -17.2700 \\
\hline 2 & -0.0160 & -0.1315 & -1.0340 & -16.0899 \\
\hline 5 & -0.0149 & -0.1218 & -0.9591 & -14.9247 \\
\hline
\end{tabular}

It is observed that the numerical solutions obtained by employing 7 terms in TSEs and using 161 equally spaced nodes in the problem domain agree very well with the analytical solution given in Fig. 5.
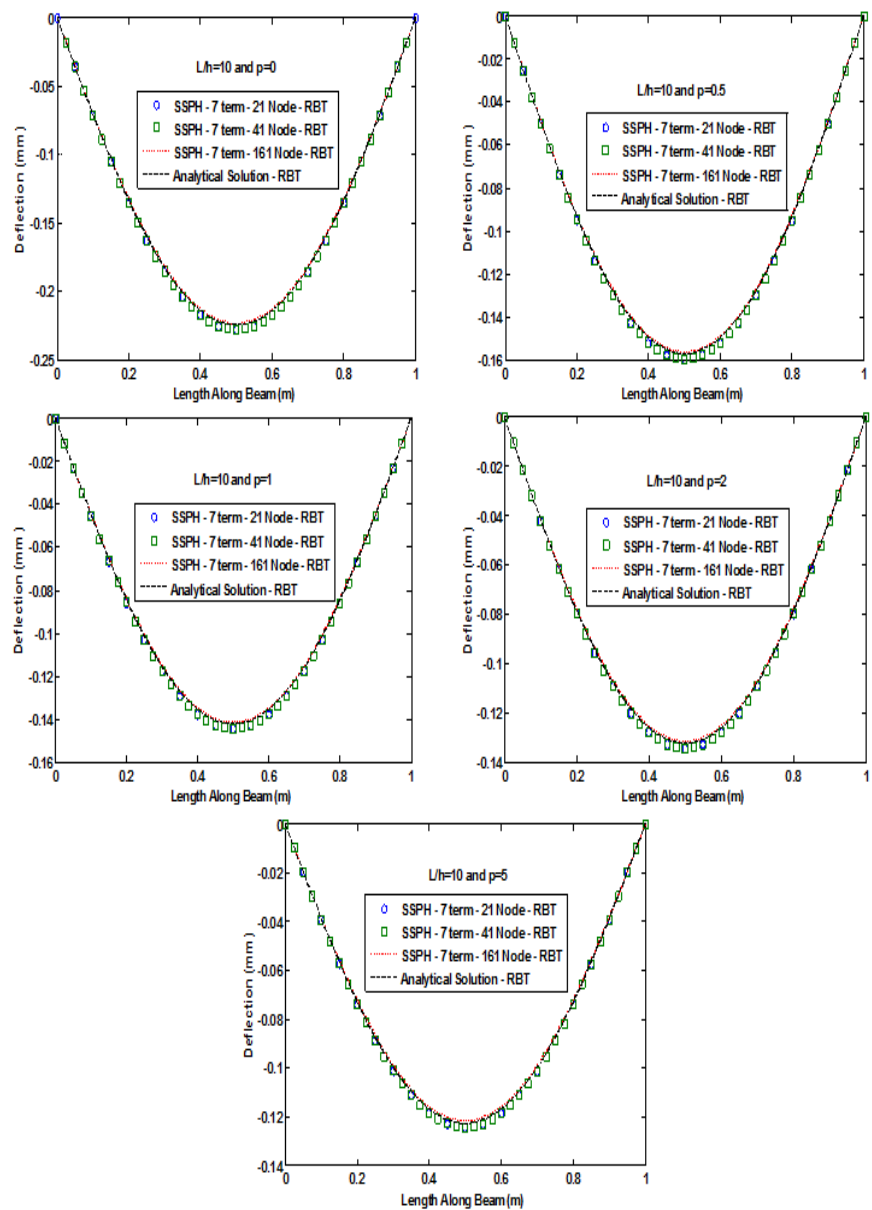

Fig. 5. Deflections of the beam computed based on the RBT and the analytical solution

\subsection{Cantilever Beam}

For a cantilever FGB the static transverse deflections under uniformly distributed load of intensity $q_{0}$ is studied as shown in Figure 6. 


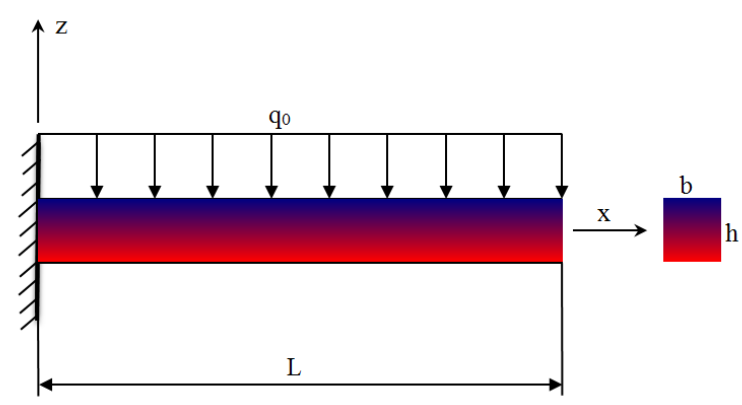

Fig. 6. Simply supported FGB with uniformly distributed load

As the physical parameters, the similar material geometry and properties are used. The uniformly distributed $\operatorname{load} q_{0}$ is set to $10000 \mathrm{~N} / \mathrm{m}$.

The governing equation of the problem is given in equation (49). The boundary conditions are given by;

$x=0, \quad \sum_{J=1}^{M} K_{2 J} W_{J}=0$ and $\sum_{J=1}^{M} K_{1 J} W_{J}=0 \mathrm{~m}$

$x=L, \quad \sum_{J=1}^{M} 2 K_{3 J} W_{J}=0$ and $\sum_{J=1}^{M} 6 K_{4 J} W_{J}=0$

The analytical solution of this boundary value problem based on the EBT is given by

$w_{0}^{E}(x)=\frac{q_{0} L^{4}}{24 D_{x x}}\left(6 \frac{x^{2}}{L^{2}}-4 \frac{x^{3}}{L^{3}}+\frac{x^{4}}{L^{4}}\right)$

The governing equations of the problem based on the TBT formulation are given in equation (51) and equation (52). The boundary conditions regarding to the TBT are given as follows;

$x=0, \quad \sum_{J=1}^{M} K_{1 J} \Phi_{J}=0$ and $\sum_{J=1}^{M} K_{1 J} W_{J}=0 \mathrm{~m}$

$x=L, \quad \sum_{J=1}^{M} K_{2 J} \Phi_{J}=0$ and $\sum_{J=1}^{M} K_{1 J} \Phi_{J}+$

$\sum_{J=1}^{M} K_{2 J} W_{J}=0$

The analytical solution of this boundary value problem based on the TBT is given by

$w_{0}^{T}(x)=\frac{q_{0} L^{4}}{24 D_{x x}}\left(6 \frac{x^{2}}{L^{2}}-4 \frac{x^{3}}{L^{3}}+\frac{x^{4}}{L^{4}}\right)+\frac{q_{0} L^{2}}{2 \kappa_{S} A_{x z}}\left(2 \frac{x}{L}-\frac{x^{2}}{L^{2}}\right)$

Based on the RBT, the governing equations of the problem are given in equation (54) and equation (55). The boundary conditions regarding to the RBT are given as follows;

$x=0, \quad \sum_{J=1}^{M} K_{1 J} \Phi_{J}=0$ and $\sum_{J=1}^{M} K_{1 J} W_{J}=0 \mathrm{~m}$

$x=L, \quad \sum_{J=1}^{M} \widehat{D}_{x x} K_{2 J} \Phi_{J}-\sum_{J=1}^{M} 2 \alpha F_{x x} K_{3 J} W_{J}=$ 0 , and $\sum_{J=1}^{M} K_{1 J} \Phi_{J}+\sum_{J=1}^{M} K_{2 J} W_{J}=0$

The analytical solution of this boundary value problem based on the TBT is given by

$w_{0}^{R}(x)=w_{0}^{E}(x)+\left(\frac{q_{0} \mu}{2 \lambda^{2}}\right)\left(\frac{\widehat{D}_{x x}}{\widehat{A}_{x z} D_{x x}}\right)\left(2 L x-x^{2}\right)+$ $\left(\frac{q_{0} \mu}{\lambda^{4} \cosh \lambda L}\right)\left(\frac{\widehat{D}_{x x}}{\hat{A}_{x z} D_{x x}}\right)[\cosh \lambda x+\lambda L \sinh \lambda(L-x)-$ $\left.\left(\frac{q_{0} \mu}{\lambda^{4}}\right)\left(\frac{\widehat{D}_{x x}}{\hat{A}_{x z} D_{x x}}\right)\left(\frac{1+\lambda L \sinh \lambda L}{\cosh \lambda L}\right)\right]$

The above boundary value problems are solved by using the SSPH method for different node distributions of 21,41 and
161 equally spaced nodes in the domain $x \in[0,1]$. The Revised Super Gauss Function given in equation (57) is used as the weight function.

For the numerical solutions, the radius of the support domain (d) is chosen as 5 and the smoothing length $(h)$ is chosen as $1.3 \Delta$. The meshless parameters, $d$ and $h$, are selected to obtain the best accuracy. Computed results by the SSPH method are compared with the analytical solutions, and their rate of convergence and accuracy properties are investigated by using the global $\mathrm{L}_{2}$ error norm given in equation (58).

In Table 8 the global $\mathrm{L}_{2}$ error norms of the solutions based on the EBT are given for different numbers of nodes in the problem domain with varying gradation exponent and 5 terms in TSEs expansion. The aspect ratio is set to 10 . The computed deflection values of the FGB are almost equal to analytical solution as seen Table 8 and Table 9. The computed transverse deflection of the beam is virtually indistinguishable from that for the analytical solution as seen from Fig. 7.

Table 8. $\mathrm{L}_{2}$ error norm for different number of nodes with varying gradation exponent $(\mathrm{p})$ and aspect ratio $\mathrm{L} / \mathrm{h}=10$ EBT

\begin{tabular}{|l|l|l|l|}
\hline \multirow{2}{*}{$\begin{array}{l}\text { Gradation } \\
\text { Exponent } \\
(\mathrm{p})\end{array}$} & \multicolumn{3}{|l|}{ Number of Nodes } \\
\cline { 2 - 4 } & 21 & 41 & 161 \\
\hline 0 & $9.3464 * 10^{-7}$ & $5.7715^{*} 10^{-6}$ & $7.7978 * 10^{-6}$ \\
\hline 0.5 & $9.3463 * 10^{-7}$ & $5.7716^{*} 10^{-6}$ & $7.8008 * 10^{-6}$ \\
\hline 1 & $9.3462 * 10^{-7}$ & $5.7715^{*} 10^{-6}$ & $7.7981 * 10^{-6}$ \\
\hline 2 & $9.3463 * 10^{-7}$ & $5.7716^{*} 10^{-6}$ & $7.7986^{*} 10^{-6}$ \\
\hline 5 & $9.3462 * 10^{-7}$ & $5.7715^{-6} 10^{-6}$ & $7.8015^{*} 10^{-6}$ \\
\hline
\end{tabular}

Table 9. Maximum deflection of the beam for different number of nodes with varying gradation exponent $(p)$ and aspect ratio $\mathrm{L} / \mathrm{h}=10-\mathrm{EBT}$

\begin{tabular}{|c|c|c|c|c|}
\hline \multirow{2}{*}{$\begin{array}{c}\text { Gradation } \\
\text { Exponent } \\
(\mathrm{p})\end{array}$} & \multicolumn{3}{|c|}{ Number of Nodes } & \multirow{2}{*}{$\begin{array}{c}\text { Analytical } \\
\text { Solution } \\
(\mathrm{mm})\end{array}$} \\
\cline { 2 - 5 } & 21 & 41 & 161 & -2.142857 \\
\hline 0 & -2.142857 & -2.142857 & -2.142856 & -1.498715 \\
\hline 0.5 & -1.498715 & -1.498715 & -1.498715 & -1.45765 \\
\hline 1 & -1.357466 & -1.357465 & -1.357465 & -1.357466 \\
\hline 2 & -1.264755 & -1.264755 & -1.264755 & -1.264755 \\
\hline 5 & - & - & - & -1.173184 \\
\hline
\end{tabular}

By using different numbers of nodes in the problem domain with 5 terms in TSEs expansion, the global $\mathrm{L}_{2}$ error norms of the solutions obtained for the TBT are given in Table 10. It is clear in Table 10 that the SSPH method provides satisfactory numerical results and rapid convergence to the analytical solution. In Table 11, maximum deflection values computed by using different number of nodes with varying gradation exponent are compared with the analytical solution. It is observed in Fig. 8 that the SSPH method agrees very well with the analytical solution. 

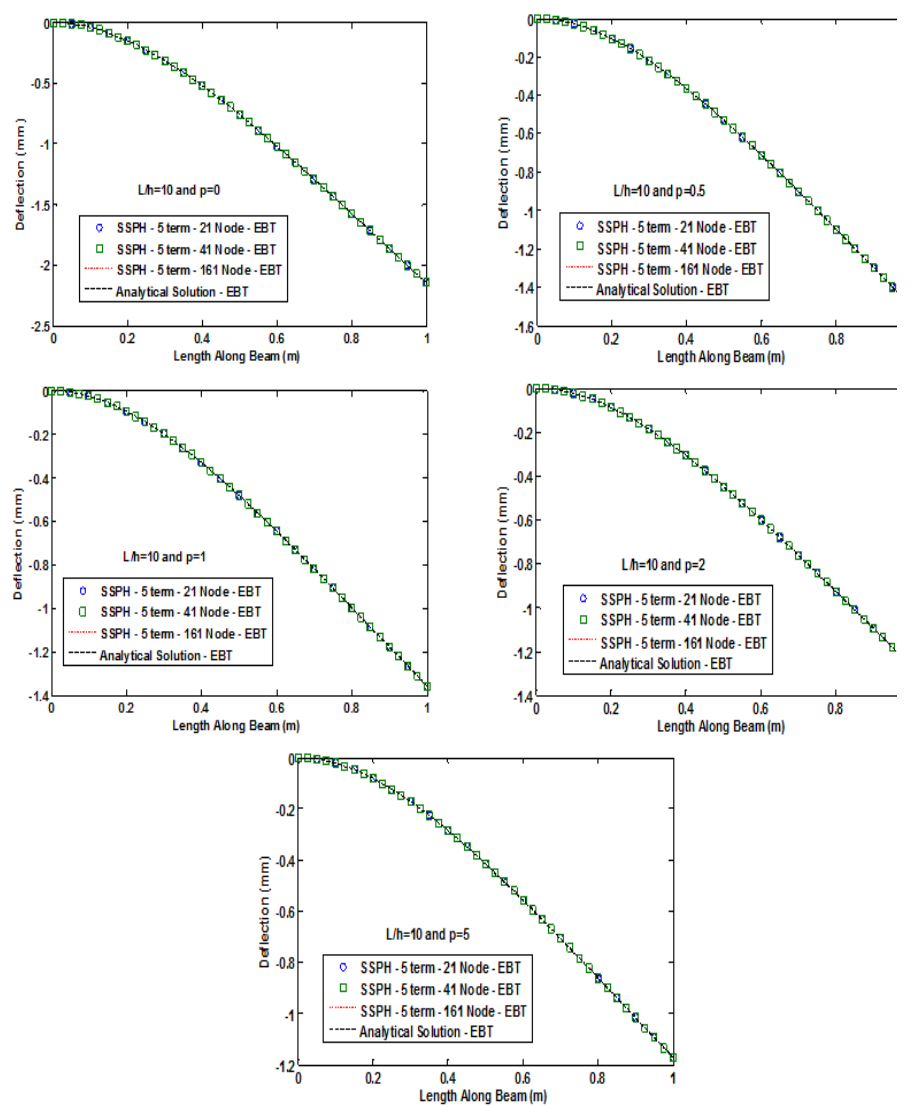

Fig. 7. Deflections of the beam computed based on the EBT and the analytical solution.

Table 10. $\mathrm{L}_{2}$ error norm for different number of nodes with varying gradation exponent $(\mathrm{p})$ and aspect ratio $\mathrm{L} / \mathrm{h}=10$ TBT

\begin{tabular}{|c|c|c|c|}
\hline \multirow{2}{*}{$\begin{array}{c}\text { Gradation } \\
\text { Exponent } \\
(\mathrm{p})\end{array}$} & 21 & 41 & 161 \\
\cline { 2 - 4 } & $1.1737 * 10^{-8}$ & $3.2575^{*} 10^{-7}$ & $6.0033^{*} 10^{-8}$ \\
\hline 0 & $1.0989 * 10^{-8}$ & $3.1489 * 10^{-7}$ & $5.3044 * 10^{-8}$ \\
\hline 0.5 & $1.1602 * 10^{-8}$ & $3.2470^{-7} 10^{-7}$ & $6.6439 * 10^{-8}$ \\
\hline 1 & $1.1786 * 10^{-8}$ & $3.4013^{-7} 10^{-7}$ & $5.8399 * 10^{-8}$ \\
\hline 2 & $1.2413 * 10^{-8}$ & $3.4943 * 10^{-7}$ & $6.5123^{*} 10^{-8}$ \\
\hline 5 & \multicolumn{3}{|c}{} \\
\hline
\end{tabular}

Table 11. Maximum deflection of the beam for different number of nodes with varying gradation exponent (p) and aspect ratio $\mathrm{L} / \mathrm{h}=10-\mathrm{TBT}$

\begin{tabular}{|c|c|c|c|c|}
\hline \multirow{2}{*}{$\begin{array}{c}\text { Gradation } \\
\text { Exponent } \\
(\mathrm{p})\end{array}$} & 21 & 41 & 161 & $\begin{array}{c}|c| \\
\text { Analytical } \\
\text { Solution } \\
(\mathrm{mm})\end{array}$ \\
\hline 0 & -2.165079 & -2.165079 & -2.165079 & -2.165079 \\
\hline 0.5 & -1.514786 & -1.514786 & -1.514786 & -1.514786 \\
\hline 1 & -1.371583 & -1.371583 & -1.371583 & -1.371583 \\
\hline 2 & -1.277342 & -1.277342 & -1.277342 & -1.277342 \\
\hline 5 & -1.184540 & -1.184540 & -1.184540 & -1.184540 \\
\hline
\end{tabular}
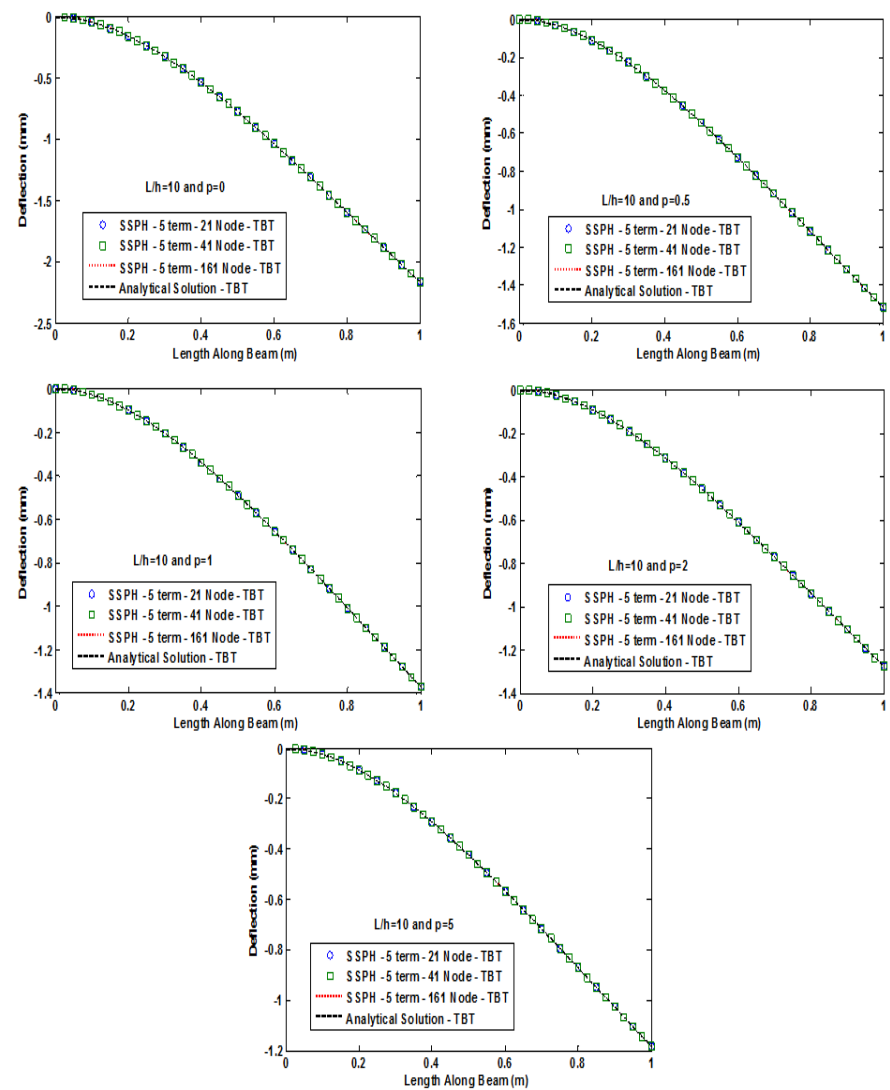

Fig. 8. Deflections of the beam computed based on the TBT and the analytical solution.

Table 12. $\mathrm{L}_{2}$ error norm for different number of nodes with varying gradation exponent $(\mathrm{p})$ and aspect ratio $\mathrm{L} / \mathrm{h}=10-5$ terms in TSEs - RBT

\begin{tabular}{|c|c|c|c|}
\hline \multirow{2}{*}{$\begin{array}{l}\text { Gradation } \\
\text { Exponent } \\
\text { (p) }\end{array}$} & \multicolumn{3}{|c|}{ Number of Nodes } \\
\hline & 21 & 41 & 161 \\
\hline 0 & 1.7557 & 1.7732 & 1.7868 \\
\hline 0.5 & 1.8593 & 1.8778 & 1.8921 \\
\hline 1 & 1.7615 & 1.7791 & 1.7927 \\
\hline 2 & 1.6317 & 1.6481 & 1.6607 \\
\hline 5 & 1.5523 & 1.5729 & 1.5850 \\
\hline
\end{tabular}

Table 13. $L_{2}$ error norm for different number of nodes with varying gradation exponent $(\mathrm{p})$ and aspect ratio $\mathrm{L} / \mathrm{h}=10-7$ terms in TSEs

\begin{tabular}{|c|c|c|c|}
\hline $\begin{array}{c}\text { Gradation } \\
\text { Exponent } \\
(\mathrm{p})\end{array}$ & 21 & 41 & 161 \\
\cline { 2 - 4 } & 1.7309 & 1.8455 & 1.5222 \\
\hline 0 & 1.8357 & 1.9472 & 1.6351 \\
\hline 0.5 & 1.7368 & 1.8512 & 1.5287 \\
\hline 1 & 1.6054 & 1.7244 & 1.3857 \\
\hline 2 & 1.5299 & 1.6518 & 1.3035 \\
\hline 5 & \multicolumn{3}{|c|}{ Number of Nodes } \\
\hline
\end{tabular}

The global $\mathrm{L}_{2}$ error norms of the solutions based on the RBT are given in Table 12 where different numbers of nodes and gradation exponents are considered with 5 terms in TSEs expansion. It is found that the number of terms in TSEs should be increased to obtain conventional convergence 
properties. The results obtained by employing 7 terms in TSEs are better than the results given in Table 12 for 161 nodes in the problem domain. It is clear that the transverse displacement computed with the SSPH method closer to the analytical solution of the problem given in Fig. 9.
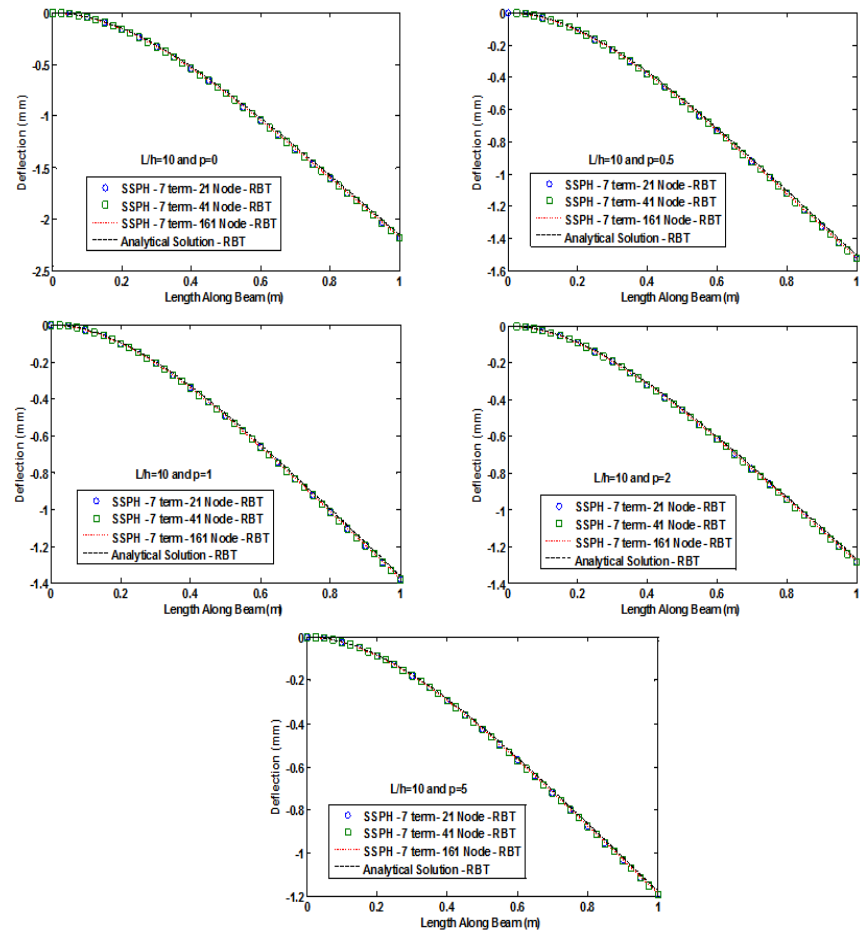

Fig. 9. Deflections of the beam computed based on the RBT and the analytical solution

\section{Conclusion}

The SSPH basis functions are employed to numerically solve the transverse deflections of the functionally graded beams subjected to different sets of boundary conditions and uniformly distributed load by using strong formulation of the problem. The numerical calculations are performed by using different number of nodes uniformly distributed in the problem domain and by employing different beam theories which are the EBT, TBT and RBT. The performance of the SSPH method is investigated for the solution of the functionally graded beam problems with the EBT, TBT and RBT for the first time. The performance of the SSPH method employing the strong formulation for the static transverse deflection analysis of the FGBs based on various beam theories are evaluated by comparing the analytical solutions which are available in the literature. It is found that the SSPH method provides satisfactory results and convergence rate for the studied problems here. It is observed that the computed values of transverse deflections agree very well with the analytical solutions. It is clear that when the EBT and TBT formulations are employed for the solution of the FGB problems by using the SSPH method, the computed results in terms of the transverse displacement are virtually indistinguishable from that for analytical solution. Based on the results of two numerical examples it is recommended that the SSPH method can be applied for solving linear functionally graded beam problems by employing different shear deformation theories.

\section{References}

[1] Sankar, B.V., An elasticity solution for functionally graded beams, Composites Science and Technology, 2001, 61, 689696

[2] Zhong, Z., Yu, T., Analytical solution of a cantilever functionally graded beam, Composites Science and Technology, 2007, 67, 481-488.

[3] Nie, G.J., Zhong, Z., Chen, S., Analytical solution for a functionally graded beam with arbitrary graded material properties, Composites Part B, 2013, 44, 274-282.

[4] Ding, H.J., Huang, D.J., Chen, W.Q., Elasticity solutions for plane anisotropic functionally graded beams, International Journal of Solids and Structures, 2007, 44, 176-196.

[5] Kadoli, R., Akhtar, K., Ganesan, N., Static analysis of functionally graded beams using higher order shear deformation theory, Applied Mathematical Modelling, 2008, $32,2509-2525$.

[6] Li, X.F., A unified approach for analyzing static and dynamic behaviors of functionally graded Timoshenko and EulerBernoulli beams, Journal of Sound and Vibration, 2008, 318, 1210-1229.

[7] Benatta, M.A., Mechab, I., Tounsi, A., Abbas, A.B.E., Static analysis of functionally graded short beams including warping and shear deformation effects, Computational Materials Science, 2008, 44, 765-773.

[8] Ben-Oumrane, S., Tounsi, A., Mechab, I., Mohamed, B.B., Mustapha, M., Abbas, A.B.E., theoretical analysis of flexional bending of $\mathrm{Al} / \mathrm{Al} 2 \mathrm{O} 3 \mathrm{~S}-\mathrm{FGM}$ thick beams, Computational Materials Science, 2009, 44, 1344-1350.

[9] Giunta, G., Belouettar, S., Carrera, E., Analysis of FGM beams by means of classical and advanced theories, Mechanics of Advanced Materials and Structures, 2010, 17, 622-635.

[10] Menaa, R., Tounsi, A., Mouaici, F., Mechab, I., Zidi, M., Bedia, E.A.A., Analytical solutions for static shear correction factor of functionally graded rectangular beams, Mechanics of Advanced Materials and Structures, 2012, 19, 641-652.

[11] Li, S.R., Cao, D.F., Wan, Z.Q., Bending solutions of FGM Timoshenko beams from those of the homogenous EulerBernoulli beams, Applied Mathematical Modelling, 2013, 37,7077-7085.

[12] Vo, T.P., Thai, H.T., Nguyen, T.K., Inam, F., Lee, J., Static behaviour of functionally graded sandwich beams using a quasi-3D theory, Composistes Part B, 2015, 68, 59-74.

[13] Filippi, M., Carrera, E., Zenkour, A.M., Static analyses of FGM beams by various theories and finite elements, Composites Part B, 2015, 72, 1-9.

[14] Jing, L.L., Ming, P.J., Zhang, W.P., Fu, L.R., Cao, Y.P., Static and free vibration analysis of functionally graded beams by combination Timoshenko theory and finite volume method, Composite Structures, 2016, 138, 192-213.

[15] Aydogdu, M., Taskin, V., Free vibration analysis of functionally graded beams with simply supported edges, Materials\&Design, 2007, 28:1651-6. 
[16] Sina S.A., Navazi H.M., Haddadpour H., An analytical method for free vibration analysis of functionally graded beams, Materials\&Design, 2009, 30:741-7.

[17] [17] Simsek, M., Fundamental frequency analysis of functionally graded beams by using different higher-order beam theories, Nuclear Engineering and Design, 2010, 240:697-705.

[18] Simsek M., Kocaturk T., Free and forced vibration of a functionally graded beam subjected to a concentrated moving harmonic load, Composite Structures, 2009, 90:465-73.

[19] Simsek, M., Vibration analysis of a functionally graded beam under a moving mass by using different beam theories, Composite Structures, 2010, 92:904-17.

[20] Sanjay, A.K., Gupta, R.K., Ramachandran, P., Venkateswara, R.G., Free vibration analysis of functionally graded beams, Defence Science Journal, 2012, 62 (3):139-46.

[21] Mahi, A., Adda Bedia E.A., Tounsi, A., Mechab, I., An analytical method for temperature-dependent free vibration analysis of functionally graded beams with general boundary conditions, Composite Structures, 2010, 92:1877-87.

[22] Pradhan, K.K., Chakraverty, S., Free vibration of Euler and Timoshenko functionally graded beams by Rayleigh-Ritz method, Composites Part B, 2013, 51:175-84.

[23] Pradhan, K.K., Chakraverty, S., Effects of different shear deformation theories on free vibration of functionally graded beams, International Journal of Mechanical Sciences, 2014, 82:149-60.

[24] Nuttawit, W., Variddhi, U., Free vibration analysis of functionally graded beams with general elastically end constraints by DTM, World Journal of Mechanics, 2012, 2:297-310.

[25] Su, H., Banerjee. J.R., Cheung, C.W., Dynamic stiffness formulation and free vibration analysis of functionally graded beams, Composite Structures, 2013, 106:854-62.

[26] Li, S.R., Wan, Z.G., Zhang, J.H., Free vibration of functionally graded beams based on both classical and firstorder shear deformation beam theories, Applied Mathematics and Mechanics, 2014, 35:591-606.

[27] Aydogdu, M., Thermal buckling analysis of cross-ply laminated composite beams with general boundary conditions, Composite Science and Technology, 2007, 67:1096-104.

[28] Aydogdu, M., Semi-inverse method for vibration and buckling of axially functionally graded beams, Journal of Reinforced Plastics\&Composites, 2008, 27:683-91.

[29] Kiani, Y., Eslami, M.R., Thermal buckling analysis of functionally graded material beams, International Journal of Mechanics and Materials in Design, 2010, 6:229-38.

[30] Huang, Y., Li, X.F., Buckling analysis of nonuniform and axially graded columns with varying flexural rigidity, Journal of Engineering Mechanics, 2011, 137(1):73-81.

[31] Shahba, A., Attarnejad, R., Marvi, M.T., Hajilar, S., Free vibration and stability analysis of axially functionally graded tapered Timoshenko beams with classical and non-classical boundary conditions, Composites: Part B 2011, 42:801-8.

[32] Nateghi, A., Salamat-talab, M., Rezapour, J., Daneshian, B. Size dependent buckling analysis of functionally graded micro beams based on modified couple stress theory. Applied Mathematical Modellling, 2012, 36:4971-87.

[33] [33] Akgöz B, Civalek Ö., Buckling analysis of functionally graded microbeams based on the strain gradient theory, Acta Mechanica, 2013; 224:2185-201.

[34] Simsek M., Buckling of Timoshenko beams composed of two-dimensional functionally graded material (2D-FGM) having different boundary conditions, Composite Structures, 2016; 149: 304-314.

[35] Donning, B.M., Liu, W.K., Meshless methods for sheardeformable beams and plates, Computer Methods in Applied Mechanics and Engineering, 1998, 152, 47-71.

[36] Gu, Y.T., Liu, G.R., A local point interpolation method for static and dynamic analysis of thin beams, Computer Methods in Applied Mechanics and Engineering, 2001, 190,42, 55155528.

[37] Ferreira, A.J.M., Roque, C.M.C., Martins, P.A.L.S., Radial basis functions and higher-order shear deformation theories in the analysis of laminated composite beams and plates, Composite Structures, 2004, 66, 287-293.

[38] Ferreira, A.J.M., Fasshauer, G.E., Computation of natural frequencies of shear deformable beams and plates by an RBFpseudospectral method, Computer Methods in Applied Mechanics and Engineering, 2006, 196, 134-146.

[39] Moosavi, M.R., Delfanian, F., Khelil, A., The orthogonal meshless finite volume method for solving Euler-Bernoulli beam and thin plate problems, Finite Elements in Analysis and Design, 2011, 49, 923-932.

[40] Wu, C.P., Yang, S.W., Wang, Y.M., Hu, H.T., A meshless collocation method for the plane problems of functionally graded material beams and plates using the DRK interpolation, Mechanics Research Communications, 2011, $38,471-476$.

[41] Roque, C.M.C., Figaldo, D.S., Ferreira, A.J.M., Reddy, J.N., A study of a microstructure-dependent composite laminated Timoshenko beam using a modified couple stress theory and a meshless method, Composite Structures, 2013, 96, 532-537.

[42] Lucy LB, A numerical approach to the testing of the fission hypothesis, Astronomical Journal, 1977, 82, 1013-1024.

[43] Chen JK, Beraun JE, Jin CJ, An improvement for tensile instability in smoothed particle hydrodynamics, Computational Mechanics, 1999, 23, 279-287.

[44] Chen JK, Beraun JE, Jin CJ, Completeness of corrective smoothed particlemethod for linear elastodynamics, Computational Mechanics, 1999, 24, 273-285.

[45] Liu WK, Jun S, Zhang YF, Reproducing kernel particle methods, International Journal for Numerical Methods in Fluids, 1995, 20, 1081-1106.

[46] Liu WK, Jun S, Li S, Adee J, Belytschko T, Reproducing kernel particle methods for structural dynamics, International Journal for Numerical Methods in Engineering, 1995, 38, $1655-1679$.

[47] Chen JS, Pan C,Wu CT, Liu WK, Reproducing kernel particlemethods for large deformation analysis of non-linear structures, Computer Methods in Applied Mechanics and Engineering, 1996, 139, 195-227. 
[48] Zhang GM, Batra RC, Modified smoothed particle hydrodynamics method and its application to transient problems, Computational Mechanics, 2004, 34, 137-146.

[49] Batra RC, Zhang GM, Analysis of adiabatic shear bands in elasto-thermo- viscoplastic materials by modified smoothed particle hydrodynamics (MSPH) method, Journal of Computational Physics, 2004, 201, 172-190.

[50] Zhang GM, Batra RC, Wave propagation in functionally graded materials by modified smoothed particle hydrodynamics (MSPH) method, Journal of Computational Physics, 2007, 222, 374-390.

[51] Batra RC, Zhang GM, Search algorithm, and simulation of elastodynamic crack propagation by modified smoothed particle hydrodynamics (MSPH) method, Computational Mechanics, 2007, 40, 531-546.

[52] Zhang GM, Batra RC, Symmetric smoothed particle hydrodynamics (SSPH) method and its application to elastic problems, Computational Mechanics, 2009, 43, 321-340.

[53] Batra RC, Zhang GM, SSPH basis functions for meshless methods, and comparison of solutions with strong and weak formulations, Computional Mechanics, 2008, 41, 527-545.

[54] Tsai CL, Guan YL, Batra RC, Ohanehi DC, Dillard JG, Nicoli E, Dillard DA, Comparison of the performance of SSPH and MLS basis functions for two-dimensional linear elastostatics problems including quasistatic crack propagation, Computational Mechanics, 2013, 51, 19-34.

[55] Tsai CL, Guan YL, Ohanehi DC, Dillard JG, Dillard DA, Batra RC, Analysis of cohesive failure in adhesively bonded joints with the SSPH meshless method, 2014, International Journal of Adhesion \& Adhesives, 51, 67-80.

[56] Karamanli A, Mugan A, Solutions of two-dimensional heat transfer problems by using symmetric smoothed particle hydrodynamics method, Journal of Applied and Computational Mathematics, 2012, 1, 1-6.

[57] Karamanli A, Bending Deflection Analysis of a Semi-Trailer Chassis by Using Symmetric Smoothed Particle Hydrodynamics, International Journal of Engineering Technologies, 2015, Vol. 1, No:4, 134-140.

[58] Karamanli A, Mugan A, Strong from meshless implementation of Taylor series method, Applied Mathematics and Computation, 2013, 219, 9069-9080.

[59] Karamanli A, Different Implementation Approaches of the Strong Form Meshless Implementation of Taylor Series Method, International Journal of Engineering Technologies, 2015, Vol. 1, No:3, 95-105.

[60] Kaewumpai, S., Luadsong, A., Two-field-variable meshless method based on moving kriging interpolation for solving simply supported thin plates under various loads. Journal of King Saud University - Science, 1018-3647, 2014.

[61] Yimnak, K., Luadsong, A., A local integral equation formulation based on moving kriging interpolation for solving coupled nonlinear reaction-diffusion equations. Advances in Mathematical Physics, 2014,

[62] Zhuang, X., Zhu, H., Augarde, C., The meshless Shepard and least squares (MSLS) method, Computational Mechanics, 53, 343-357, 2014.

[63] Fatahi, H., Nadjafi, JS, Shivanian, E, New spectral meshless radial point interpolation (SMRPI) method for the two- dimensional Fredholm integral equations on general domains with error analysis, Journal of Computational and Applied Mathematics, 264, 196-209, 2016.

[64] Love, A.E.H., 1927, A Treatise on the Mathematical Theory of Elasticity, fourth ed. Dover Publications, New York.

[65] Timoshenko, S.P., Goodier, J.C., 1970, Theory of Elasticity, McGraw-Hill Co. Inc., New York.

[66] Wang, C.M., Reddy, J.N., Lee, K.H., 2000, Shear Deformable Beams and Plates Relations with Classical Solutions, Elsevier Science Ltd., Oxford.

[67] Polizzotto, C., 2015, From the Euler-Bernoulli beam to the Timoshenko one through a sequence of Reddy-type shear deformable beam models of increasing order, European Journal of Mechanics A/Solids, 53, 62-74.

[68] Levinson, M., 1981. A new rectangular beam theory, Journal of Sound and Vibration, 74, 81-87.

[69] Bickford, W.B., 1982. A consistent higher order beam theory, Developments in Theoretical and Applied Mechanics, 11, 137-150.

[70] Heyliger, P.R., Reddy, J.N., 1988, A higher order beam finite element for bending and vibration problems, Journal of Sound and Vibration, 126 (2), 309-326.

[71] Subramanian, P., 2006, Dynamic analysis of laminated composite beams using higher order theories and finite elements, Composite Structures, 73, 342-353.

[72] Reddy, J.N., 2007, Nonlocal theories for bending, buckling and vibration of beams, International Journal of Engineering Science, 45, 288-307.

[73] Carrera, E., Giunta, G., 2010, Refined beam theories based on a unified formulation, International Journal of Applied Mechanics, 2 (1), 117-143.

[74] Giunta, G., Biscani, F., Bellouettar, S., Ferreira, A.J.M., Carrera, E., 2013, Free vibration analysis of composite beams via refined theories, Composites Part B, 44, 540-552.

[75] Arya, H., 2003, A new zig-zag model for laminated composite beams: free vibration analysis, Journal of Sound and Vibration, 264, 485-490.

[76] Jun, L., Hongxing, H., 2009, Dynamic stiffness analysis of laminated composite beams using trigonometric shear deformation theory, Composite Structures, 89, 433-442.

[77] Kurama, M., Afaq, K.S., Mistou, S., 2003, Mechanical behavior of laminated composite beams by the new multilayered laminated composite structures model with trigonometric shear stress continuity, International Journal of Solids and Structures, 40, 1525-1546. 